\title{
Combination of Multiple Dental Anomalies in Healthy Patient: A Case Report
}

Haneen Alshukairi ${ }^{1}$

\begin{abstract}
Aim and objective: The aim and objective of this paper is to report a combination of various dental anomalies in a healthy pediatric patient. Background: A combination of dental anomalies was reported, particularly in patients with syndromes or chromosomal abnormality. Very few cases of multiple defects have been described in patients with no generalized abnormality.

Case description: This article reports the case of a 10-year-old female healthy patient who was found to have multiple dental anomalies which include: (1) bilateral congenitally missing 2nd premolar, (2) bilateral peg laterals, (3) an abnormal sequence of eruption in the lower right side, and (4) delayed eruption of lower left canine.

Conclusion: Dental anomalies have multiple effect on the occlusion as well as on the esthetic. Early diagnosis and intervention and collaboration between the different subspecialty are needed.

Clinical significance: Pedodontics, orthodontic, restorative, and prosthodontic consultation was taken for the best future proposed treatment that ranges between orthodontics space closure, implants, and esthetic treatment for the peg laterals.

Keywords: Congenitally missing, Multiple anomalies, Peg lateral

International Journal of Clinical Pediatric Dentistry (2021): 10.5005/jp-journals-10005-2093
\end{abstract}

\section{INTRODUCTION}

Dental anomalies are caused by complex multifactorial interaction and environmental factors. ${ }^{1}$ Different studies assessed the prevalence of various dental abnormalities world wise. ${ }^{2}$

Dental agenesis is one of the most common dental anomalies that dentists started to investigate in the early 1990 s. $^{3} \mathrm{~A}$ tooth that could not be identified radiographically, based on calcification, is diagnosed as congenitally missing, with no evidence of extraction. ${ }^{4}$

Hypodontia is the terminology used to describe the developmental absence of one or more primary or permanent teeth, excluding the third molars. It is the most commonly reported dental anomaly and is more frequent in the permanent dentition. ${ }^{3}$

Congenitally missing teeth were almost equally distributed between maxillary and mandibular arches. ${ }^{5}$

The prevalence of children with hypodontia was found to be $2.6 \%$. The mandibular second premolar was the tooth most frequently absent and accounted for $45 \%$ of the total missing teeth. In the primary dentition, the maxillary lateral incisor was the tooth most frequently lacking (9\%). A peg-shaped permanent maxillary lateral incisor was present in $0.7 \%$ of the sample. ${ }^{5}$

In Saudi children, it was reported that hypodontia (9.7\%) is the most common anomaly in, followed by hyperdontia $(3.5 \%)$. The prevalence of size anomalies such as microdontia (2.6\%) and macrodontia (1.8\%) was reported subsequently. ${ }^{6}$

Abnormalities in tooth eruption timing and sequence are often caused by genetic or environmental factors and result in malocclusion. Early diagnosis and interaction are highly recommended?

A combination of dental anomalies was reported, particularly in patients with syndromes or chromosomal abnormality. Very few cases of multiple defects have been described in patients with no generalized abnormality. ${ }^{1}$ We are reporting various dental anomalies in a healthy patient.
${ }^{1}$ Preventive Dentistry Department, Riyadh Elm University, Riyadh, Al Saudi Arabia

Corresponding Author: Haneen Alshukairi, Preventive Dentistry Department, Riyadh Elm University, Riyadh, Saudi Arabia, e-mail: haneen@doctor.com

How to cite this article: Alshukairi H. Combination of Multiple Dental Anomalies in Healthy Patients: A Case Report. Int J Clin Pediatr Dent 2021;14(6):825-827.

Source of support: Nil

Conflict of interest: None

\section{Case Description}

A 10-year-old healthy female patient presented to the dental clinic with her mother complaining of a loose tooth. But, the mother was concerned about the eruption sequence of the teeth, as it was not the same as the opposite one.

On clinical examination, tooth \#84 was highly mobile and ready for exfoliation, and tooth \#83 was also mobile but at a lower degree. On the other hand, the sequence of the eruption in the opposite quadrant was different. Tooth \#73 exfoliated 6 months ago, and clinically only the tip of the permanent succedaneous canine is showing. However, tooth \#74 was still present with mild mobility only (Figs 1 and 2). Besides, during the examination, it was recognized that the patient is also having two pegs lateral incisor (Figs 3 and 4). A detailed history taken from the mother regarding any hereditary or congenital development defect in teeth: she reported a positive history of one missing lower posterior tooth in her aunt.

A panoramic X-ray was taken to assess the whole dental condition, also, two bitewings and a selective periapical X-ray (Figs 4 and 5). Radiographic interpretation showed that the patient 
is having bilaterally congenitally missing upper second premolar. Full set of clinical picture was taken after a written consent from the parents.

In conclusion, the patient was diagnosed to have multiple dental anomalies: (1) bilateral congenitally missing 2nd premolar, (2) bilateral peg laterals, (3) an abnormal sequence of eruption in the lower right side, and (4) delayed eruption of lower left canine.

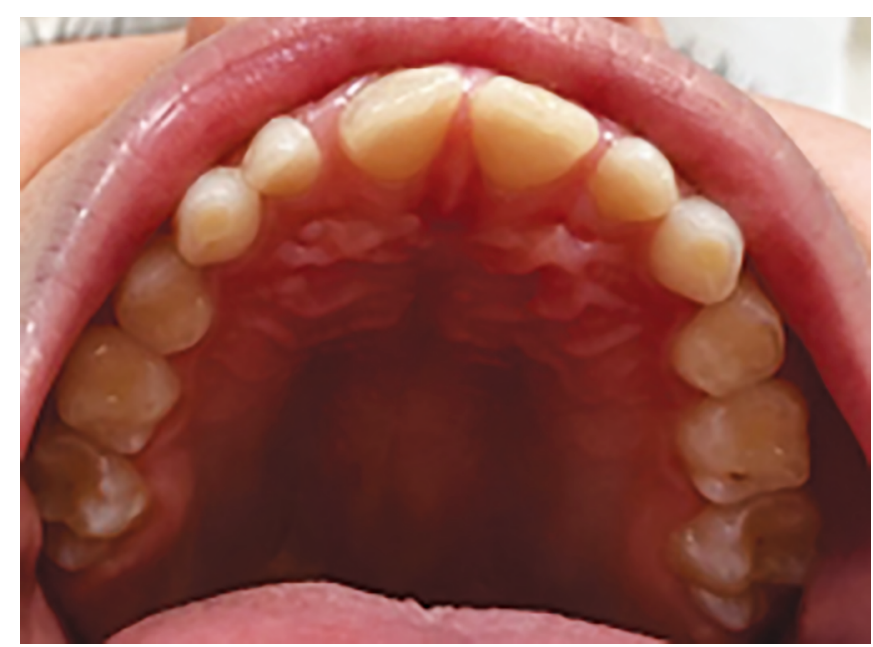

Fig. 1: Upper arch with congenitally missing molars

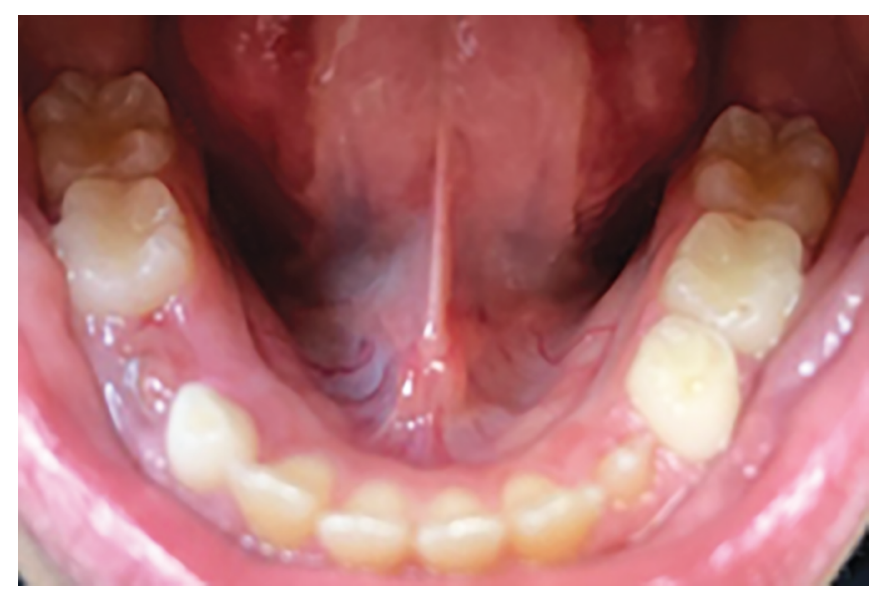

Fig. 2: Delayed eruption of canine and abnormal sequence of eruption of \#84

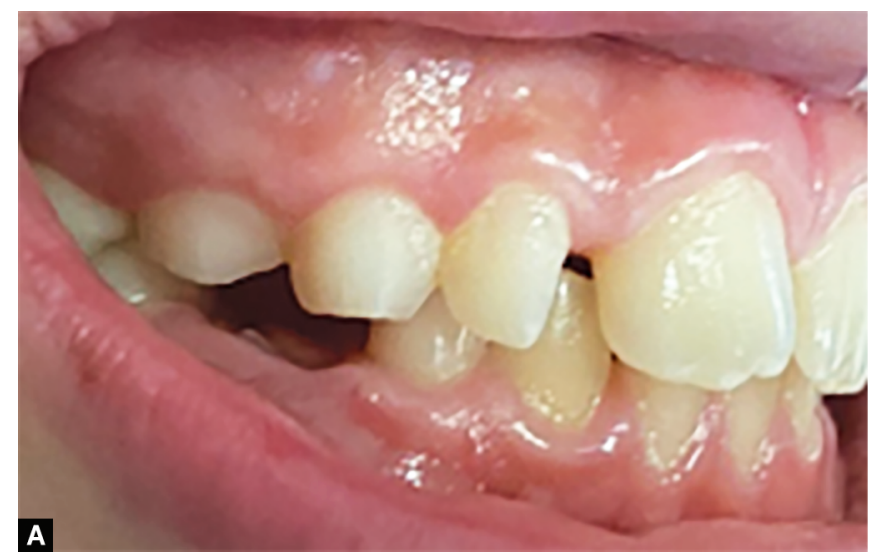

Figs $3 \mathrm{~A}$ and B: Peg laterals
Orthodontic and restorative consultation was taken for the best future proposed treatment that ranges between orthodontics space closure, implants, and esthetic treatment for the peg laterals.

\section{Discussion}

During the mixed dentition, assessment of the teeth in both jaws is essential; multiple dental anomalies can be detected during this age group. Early detection and intervention can avoid a lot of malocclusions (1). Multiple defects in the healthy patient were not commonly reported. Our patient presented with numerous defects; the most significant one by that age is the missing 2 nd premolar.

A different study supported the findings that numerical anomalies are the most prevalent form, as similar to the one mentioned by Backman and Wahlin. ${ }^{8}$ Dental agenesis can be classified into two groups-total and partial agenesis: Total agenesis or anodontia is defined as the complete absence of all teeth. It is a sporadic condition with an autosomal recessive pattern of inheritance. ${ }^{9,10}$ Partial agenesis is subdivided into two typeshypodontia and oligodontia. ${ }^{11}$

Familial hypodontia could be autosomal dominant, autosomal recessive, or sex-linked patterns of inheritance, ${ }^{12}$ which looks like our case, as only one aunt had the same anomalies but in a different quadrant.

However, partial agenesis can also occur without familial history. It can result from perturbation during initial stages of tooth development, such as trauma, localized inflammation, or ectodermal dysplasia. It can also be associated with systemic problems such as syphilis or rickets. However, it is usually an isolated condition due to the mutation of gene MSX1 and PAX9.9,10,13

In our case, the patient is having the second premolar missing, which is the third common missing tooth. After the third molar, the most commonly missing permanent teeth are mandibular second premolars and maxillary lateral incisors or maxillary second premolars. $^{14}$

One study in Aseer, Saudi Arabia ${ }^{15}$ reported that the prevalence of congenitally missing maxillary second premolars was $25.64 \%$ that comes into 2 nd place after mandibular second premolars that was $28.21 \%$. Similar results were reported by different research. ${ }^{16,17}$ However, this is in contrast with findings by Emran, who mentioned that the maxillary lateral incisors were the most frequently missing teeth in Saudi Arabian School children than mandibular second premolar. ${ }^{6,18}$

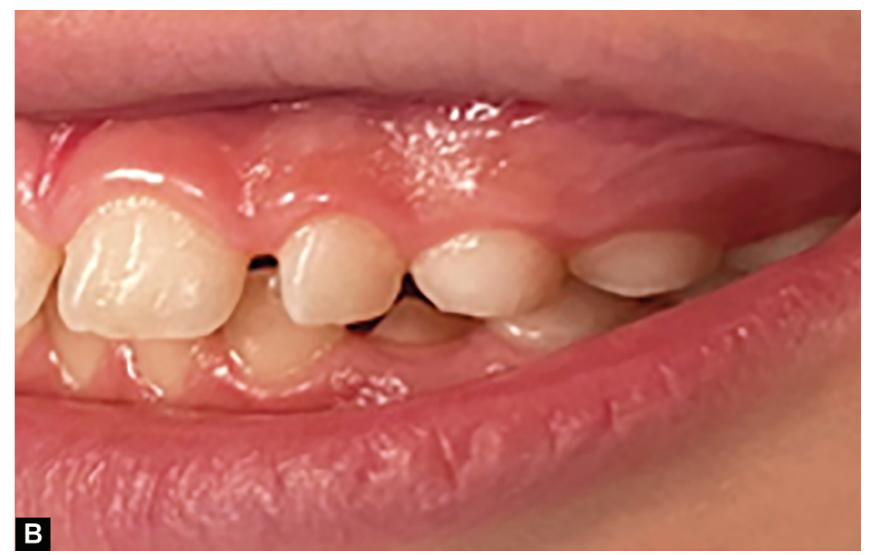




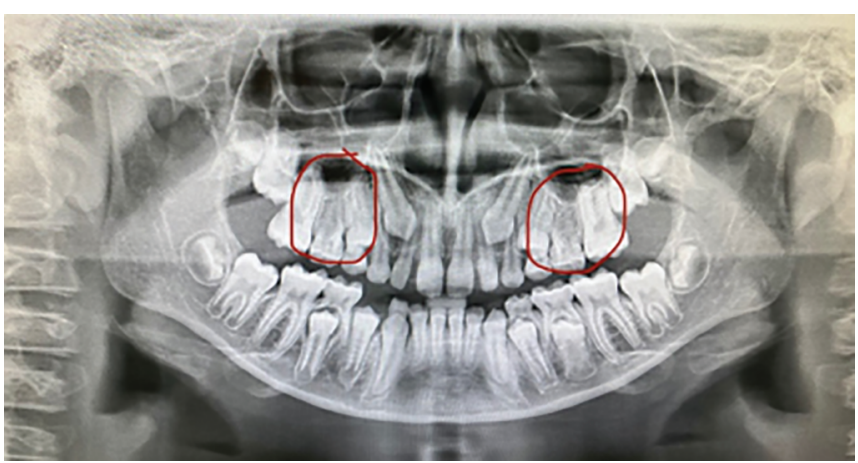

Fig. 4: Congenitally missing 15 and 25

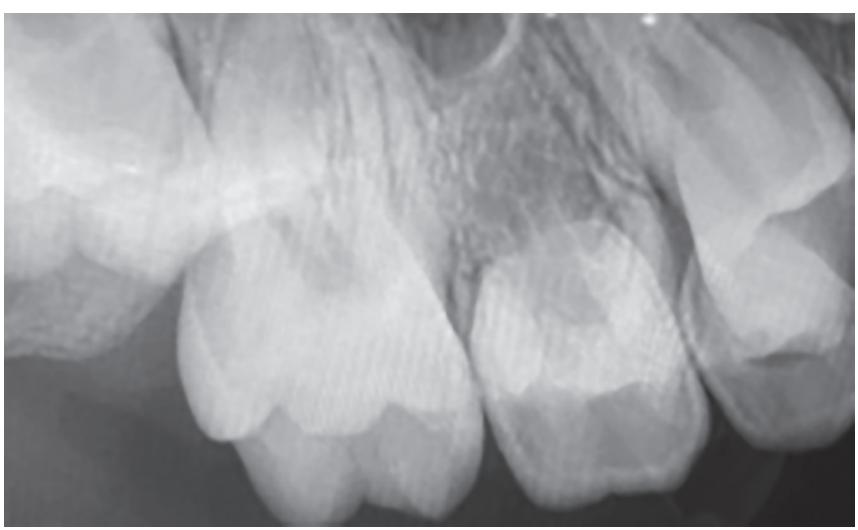

Fig. 5: Congenitally missing 15 and 25

Our patient was also diagnosed to have a lateral peg tooth, which is not as common as the hypodontia. Jaha reported that in Saudi Arabia, congenitally missing tooth was the most common anomaly (2.1\%), followed by tooth impaction ( $0.9 \%)$, and lastly, was the peg-shaped lateral (0.6\%). ${ }^{19}$ This kind of anomalies is the least difficult in term of treatment, as the shape of the tooth can be easily corrected with esthetic restoration.

The sequence of eruption and the timing of eruption are not of clinical importance at the age of the patients, as she seems to have a generalized delay in eruption and follow-up is recommended. Al-Jasser NM et al. considered many reasons as influential factors on the time and order of teeth emergence. These include nutrition, socioeconomic status, sex, climate, and premature extraction of the deciduous teeth. ${ }^{20}$ They suggest a slightly delayed eruption of the teeth in Saudi children compared to those of Caucasian children, ${ }^{21}$ but the results were similar to those reported for Iraqi children. ${ }^{22}$

\section{ConCLusion}

Dental agenesis has a significant impact on treatment planning and space management during mixed dentition. It is a challengeable issue for orthodontists and pedodontists. However, when it is combined with other dental anomalies, more comprehensive evaluation and treatment should be taken in consideration at an earlier stage.

\section{Clinical Significance}

Orthodontic, restorative, and prosthodontic consultation was taken for the best future proposed treatment that ranges between orthodontics space closure, implants, and esthetic treatment for the peg laterals.

\section{References}

1. Nagaveni NB. An unusual occurrence of multiple dental anomalies in a single nonsyndromic patient: a case report. Case Rep Dent 2012;2012:426091. DOI: 10.1155/2012/426091

2. Roslan AA, Rahman NA, Alam MK, Dental anomalies and their treatment modalities/planning in orthodontic patients. J Orthod Sci 2018;7:16. DOI: 10.4103/jos.JOS_37_18

3. Reddy N. Congenitally missing teeth: a case report. Ann Essenc Dent 2010;2(1):5-9.

4. White SC, Pharoah MJ, O'Connor D. Oral Radiology: Principles and Interpretation, 5th edition. St. Louis, Mo, USA: Mosby; 2004.

5. Salama FS, Abdel-Megid FY. Hypodontia of primary and permanent teeth in a sample of Saudi children. Egypt Dent J 1994;40(1): 625-632.

6. Yassin SM. Prevalence and distribution of selected dental anomalies among Saudi children in Abha, Saudi Arabia. J Clin Exp Dent 2016;8(5):e485-e490. DOI: 10.4317/jced.52870

7. Devraj IM, Bhojraj N, Narayanappa. Polymorphism in the eruption sequence of primary dentition: a cross-sectional study. J Clin Diagn Res 2017;11(5):ZC72-ZC74. DOI: 10.7860/JCDR/2017/27668.9909

8. Backman B, Wahlin YB. Variations in number and morphology of permanent teeth in 7-year-old Swedish children. Int J Paediatr Dent 2001;11:11-17. DOI: 10.1046/j.1365-263x.2001.00205.x

9. Silverman N, Ackerman J. Oligodontia: a study of its prevalence and variation in 4032 children. ASDC J Dent Child 1979;46(6):470-477.

10. McDonald RE, Avery DR, Hartsfield JK. Acquired and developmental disturbances of the teeth and associated oral structures. In: Dean JA, Avery DR, McDonald RE (Eds). McDonald and Avery Dentistry for the Child and Adolescent. 9th edition. St. Luis: Mosby; 2011. pp: $85-125$.

11. JahanimoghadamF,TorabiM,RostamiS. (2015).Case report:congenitally missing teeth. [online] Available fromhttp://anatomyjournal.ir/article1-113-en.pdf. [Last accessed November, 2021].

12. Woolf CM. Missing maxillary lateral incisors: a genetic study. Am J Hum Genet. 1971;23(3):289.

13. Dummett $C$ Jr. Anomalies of the developing dentition Pinkham JR, Casamassimo P, Fields HW, McTigue D, Nowak A (Eds). Pediatric Dentistry: Infancy through Adolescence, 4th edition. Philadelphia, PA: Mosby; 2005. pp. 61-73.

14. Proffit WR, Fields HW Jr, Sarver DM. Contemporary orthodontics, 5th edition. St. Louis: Mosby Co; 2013. pp. 453-455.

15. Tariq Ali GP. (2017). Prevalence of congenitally missing permanent teeth in Asir region, Kingdom of Saudi Arabia. [online] Available fromhttps://www.pulsus.com/proceedings/prevalence-ofcongenitally-missing-permanent-teeth-in-asir-region-kingdom-ofsaudi-arabia-142.html. [Last accessed November, 2021].

16. Behr M, Proff $P$, Leitzmann $M$, et al. Survey of congenitally missing teeth in orthodontic patients in Eastern Bavaria. Eur J Orthod 2011;33:32-36. DOI: 10.1093/ejo/cjq021

17. Endo T, Ozoe R, Yoshino S, et al. Hypodontia patterns and variations in craniofacial morphology in Japanese orthodontic patients. Angle Orthod 2006;76:996-1003. DOI: 10.2319/082905-303

18. Al-Emran S. Prevalence of hypodontia and developmental malformation of permanent teeth in Saudi Arabian school children. Br J Orthod 1990;17:115-118. DOI: 10.1179/bjo.17.2.115

19. Jaha HS, Sharaf R. The prevalence of tooth transposition and the possible associated anomalies in patient seeking orthodontic treatment in Jeddah, Saudi Arabia. Oral Health Dent Manag 2017;6(Suppl):35. DOI: 10.4172/2247-2452-C1-063

20. Al-Jasser NM, Bello LL. Time of eruption of primary dentition in children from Saudi Arabia. J Contemp Dent Pract 2003;4:65-75.

21. Magnusson TE. Emergence of primary teeth and onset of dental stages in Icelandic children. Community Dent Oral Epidemiol 1982 Apr;10(2):91-97. DOI: 10.1111/j.1600-0528.1982.tb00370.x.

22. Baghdady VS, Ghose LJ. Eruption time of primary teeth in Iraqi children. Community Dent Oral Epidemiol 1981;9(5):245-246. DOI: 10.1111/j.1600-0528.1981.tb00338.x 